\title{
Mechanical properties of the Al-Mg/MWCNTs composite powders: The effects of ball milling process parameters
}

Hossein Ahmadian ( $\square$ hosseinahmadian@live.com )

Beijing Institute of Technology

\section{Research Article}

Keywords: Ball Milling, Al-Mg matrix, MWCNTs, plastic deformation, crystallite size, intermetallic phases

Posted Date: August 31st, 2021

DOI: https://doi.org/10.21203/rs.3.rs-845761/v1

License: (c) (i) This work is licensed under a Creative Commons Attribution 4.0 International License.

Read Full License 


\title{
Mechanical properties of the Al-Mg/MWCNTs composite powders: The effects of ball milling process parameters
}

\author{
Hossein Ahmadian ${ }^{1, *}$ \\ 1- School of Mechanical Engineering, Beijing Institute of Technology, Beijing, China. \\ *Corresponding author: hosseinahmadian@live.com
}

\begin{abstract}
The effects of multi-walled carbon nano-tubes (MWCNTs) and the ball milling parameters on the mechanical properties of the Al-Mg alloy powders were investigated. Three different composite powders were synthesized through ball-milling process at different time and milling rates. The microstructural and phase analyses were carried out via scanning electron microscopy and X-ray diffraction spectroscopy, respectively. The results indicated that increasing the ball-milling time and rate would lead to the formation of finer particles, which consequently intensifies the plastic deformation and then, results in lower crystallite size. The morphological investigations indicated that while the MWCNTs agglomerates in lower milling rates, increased milling rate not only improve the distribution of the MWCNTs, but also decreases the length of the nano-tubes and promotes their diffusion into Al-Mg matrix. The formation of Al-Mg intermetallic phases through the ball-milling process of the composite powders was also confirmed via microstructural investigations.
\end{abstract}

Keywords: Ball Milling, Al-Mg matrix, MWCNTs, plastic deformation, crystallite size, intermetallic phases.

\section{Introduction}

Powder metallurgy (PM) methods have been recently attended by researchers for manufacturing CNTreinforced metal matrix composites (MMCs), due to their relatively simple processing as well as their adjustability [1,2]. Among the MMCs, aluminum-matrix composites have found extended applications in last years, which promote the researches on enhancing the strength and elastic modulus of the materials, as well as improving their corrosion behavior. Ball-milling (BM) is known as one of the simplest technics to homogenize the distribution of the fine reinforcement particles in the metal matrixes [3-5]. Specifically, high-energy ball-milling (HEBM) not only facilitate the homogenous distribution of the reinforcement in powder matrix, but also simultaneously results in finer metal powder particles through cracking and crashing the raw particles [6-8]. The repeated cold-welding/crushing of the particles induced by the BM method, also influences the mechanical, physical, and chemical properties of the powder particles. Hence, the process parameters of the ball-milling such as rotation rate, ball/powder ratio, and the milling time should be accurately controlled to achieve the final product with favorable properties [9].

Aluminum alloys are widely applied in several industries including automobile, aerospace, and transportation, thanks to their unique combination of properties such as low density $(2.7 \mathrm{~g} . \mathrm{cm}-3)$, low melting point $\left(660^{\circ} \mathrm{C}\right)$, good formability and excellent corrosion resistance [10-12]. However, more promising outcomes have also been achieved through aluminum matrix composites. Improved properties 
through manufacturing Al-matrix composites have led to lower production and maintenance cost as well as fuel consumption, which are economically favorable factors for materials development [10, 12-13].

Magnesium and Mg-based alloys present a combination of properties including high strength and stiffness, as well as the attenuation ability. This group of metallic alloys with the density of $1.74 \mathrm{~g} . \mathrm{cm}-3$, provides structures $40 \%$ and $80 \%$ lighter than aluminum and steels, respectively [10, 14-15]. Hence, Mg-based materials have been widely used in Al-Mg alloys to enhance the specific strength and corrosion resistance, mainly in Al-MMCs $[16,17]$. Several research works have been dedicated to the Al-Mg alloy system including different reinforcements. For instance, Eltaher et. al reported that the addition of only 5 wt.\% nano-Al2O3 particles results in $94.2 \%$ and $81.8 \%$ increment in hardness and compressive strength of the Al-Mg matrix, respectively [18].

Carbon nano-tubes (CNTs) are well-known reinforcement in metal-matrix-nano-composites, due to their excellent mechanical properties such as superior tensile strength (150 GPa) and high elastic modulus (1TPa). Hence, CNTs have been extensively used to reinforce the nano-composites [19-21]. Significant increase in the mechanical properties of the commercially pure aluminum has been reported by Rikhtegar et. al. They used 1.5 wt.\% CNTs to reinforce the Al-MMCs manufactured through semi-wet (SW) and slurry-based (SB) methods, and found increased yield and ultimate tensile strengths from 90 and $136 \mathrm{MPa}$ to 110 and $170 \mathrm{MPa}$ in SW method, respectively. Through the SB method, 152 and $203 \mathrm{MPa}$ were obtained as YS and UTS of the material, respectively [22]. Al-matrix composites reinforced with 2 and 4 vol\% CNTs were produced by Akbarpour et. al through hot-pressing method. They found that while 35 and $50 \%$ reduction in the crystallite size is observed in 2 and 4 vol\% CNT-reinforced composites respectively, increased CNT content can result in about 30\% enhancement of YS and UTS of the material [23].

Nevertheless, excellent research works which have been carried out on Al-CNTs composites through last years, the effects of multi-walled carbon nano-tubes (MWCNTs) on the properties of the Al-based composites have not been deeply investigated yet. Hence, this study is dedicated to the synthesis of AlMg-MWCNTs triple composite through mechanical alloying and ball-milling process. The effects of process parameters such as milling duration (time) and rate on the properties of the final products have also been investigated in this study.

\section{Experimental}

\subsection{Materials}

Commercially pure aluminum and magnesium powders (average particle sizes of 45 and $100 \mu \mathrm{m}$, respectively, Sigma-Aldrich) as well as multi-walled carbon nano-tubes (outer diameter of 20-30 nm, length of $10-30 \mu \mathrm{m}$, purity $>95 \%$, US Research Nanomaterials) were used as the starting materials. Fig. 1 shows the morphological SEM micrographs of the raw materials.

The starting materials were weighed and mixed according to the equation (1):

$A l-(1-x) M g-x M W C N T s, \quad x=0,2 w t . \%$ 

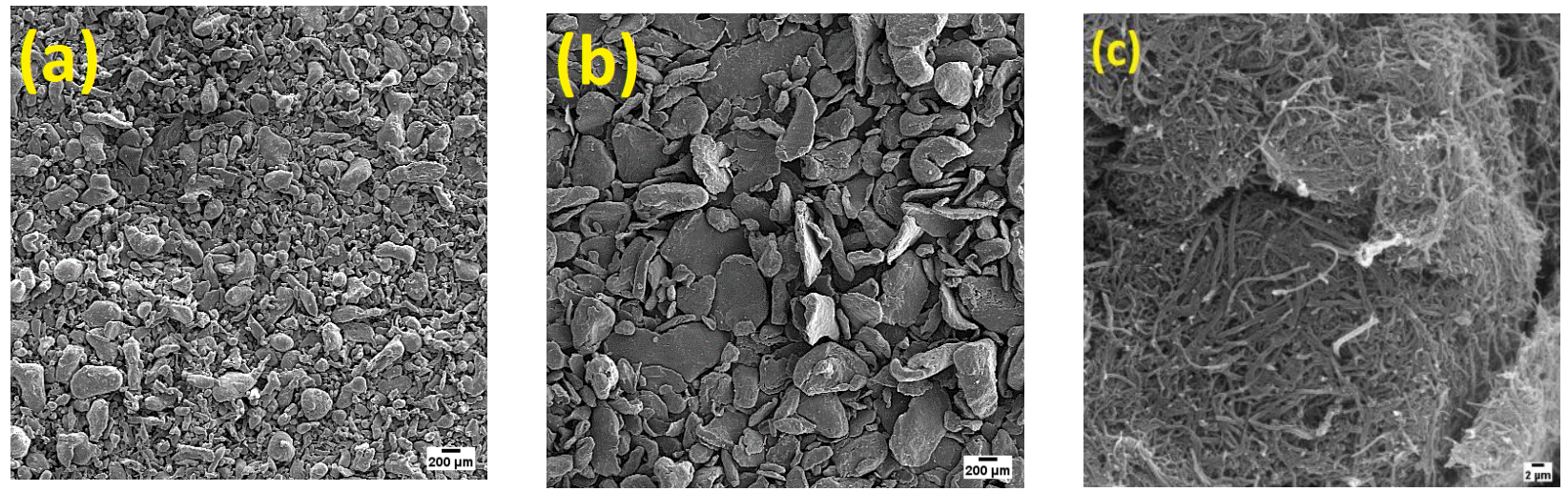

Fig. 1. SEM micrographs of (a) Al, (b) Mg powders and (c) MWCNTs used in this study.

\subsection{Ball Milling}

The powder mixtures were then ball-milled in stainless steel cups at room temperature under the argon atmosphere (BPR: 10:1, stainless steel balls with a diameter of $15 \mathrm{~mm}$ ). The mechanical alloying processes were performed at 300 and $400 \mathrm{rpm}$ for 1, 4, 7, and 10 hours, and $3 \mathrm{wt} . \%$ stearic acid was used as the process control agent (PCA) to minimize the cold-welding and oxidation of the powder particles through all the milling runs, and a quarter hour of a break was given for every 1 hour of work. Three groups of the samples were prepared including mixed and milled Al/Mg (milled Al-Mg), mixed and milled Al-Mg-MWCNT (MM Al-Mg-MWCNT), and MWCNT-added milled Al-Mg (double milled Al-Mg-MWCNT). While in the first and second groups the raw materials were initially mixed and milled, in the last group, the mixture of $\mathrm{Al}$ and $\mathrm{Mg}$ were initially ball milled for 15 hours at $500 \mathrm{rpm}$, and then mixed and milled with the MWCNTs up to 10 hours. The experimental conditions process of this study are presented in Table 1.

\begin{tabular}{|c|c|c|c|}
\hline Experimental conditions & Milled Al-Mg & MM Al-Mg-MWCNT & Double milled Al-Mg-MWCNT \\
\hline Rotation speed [rpm] & \multicolumn{3}{|c|}{$300,400,(500$ for special condition) } \\
\hline Grinding time [hour] & \multicolumn{3}{|c|}{$1,4,7,10,(15$ for special condition) } \\
\hline Ball diameter $[\mathrm{mm}]$ & \multicolumn{3}{|c|}{15} \\
\hline Ball powder ratio & \multicolumn{3}{|c|}{ 10:1 (All samples) } \\
\hline Amount of MWCNTs & \multicolumn{3}{|c|}{0 wt. $\% 2$ wt.\% } \\
\hline Material & \multicolumn{3}{|c|}{ Stainless Steel } \\
\hline Temperature & \multicolumn{3}{|c|}{ Room Temperature } \\
\hline Atmosphere & \multicolumn{3}{|c|}{ Argon } \\
\hline
\end{tabular}

Table 1. experimental conditions process. 


\subsection{Morphological analysis \& Structural evolutions}

The prepared samples were then characterized via a scanning electron microscope (SEM, VEGA-TESCAN$\mathrm{XMU}$ ) and a field emission scanning electron microscope (FESEM: MIRA3-TESCAN). Phase analysis of the samples was also performed using X-ray diffraction spectroscope (XRD, Phillips PW1730). The XRD pattern of the samples were obtained in $2 \theta$ range of $20-80^{\circ}$, step size of $0.05^{\circ}$, and the scan rate of 1 degree per minute. The crystallite size and the lattice strain of the aluminum-based composite powders were calculated based on the William-Hall equation [24] (Eq. 2):

$B \cos \theta=\frac{0.9 \lambda}{D}+4 \varepsilon \sin \theta$

In which, $B, \lambda, \theta, D$, and $\varepsilon$ show full width in half maximum, wavelength, peak position, crystallite size, and lattice strain, respectively.

\section{Results and discussion}

\subsection{Morphological investigations}

The SEM micrographs of the milled Al-Mg samples at the rate of 300 and $400 \mathrm{rpm}$ for 1, 4, 7, 1nd 10 hours are presented in Fig. 2. Compared with Fig. 1, Fig. 2a shows the crashed and deformed Al and Mg particles after milling for 1 hour at $300 \mathrm{rpm}$. Further increasing the milling time at the constant rate of $300 \mathrm{rpm}$ (4 and $7 \mathrm{~h}$ ) seems to not significantly change the particle size. However, increasing the milling time to $10 \mathrm{~h}$ has led to increased particle size, which addresses the occurrence of cold-welding phenomenon. Compared to Fig. 2a, Fig. $2 \mathrm{~b}$ shows higher efficiency of the milling process at the rate of $400 \mathrm{rpm}$ in which, finer particles of $\mathrm{Al}$ and $\mathrm{Mg}$ have been achieved in all the milling times. Even after $10 \mathrm{~h}$ of milling, Fig. $2 \mathrm{~b}$ shows decreased particle size which can be attributed to the continuous crashing of the particles without any cold-welding through the milling process at $400 \mathrm{rpm}$. The highly deformed morphology of the powder particles in Fig. $2 \mathrm{~b}$ also addresses the progression of mechanical alloying, derived by the interaction between balls and the powder particles that leads to the flake morphology of the initial particles. Such phenomenon also confirms the direct relationship between the milling time and plastic deformation of the powder particles, which has led to higher degree of deformation in particles ball-milled for longer period [9].

Based on the finer size of the particles shown in Fig. 3 (SEM micrographs of the MM Al-Mg-MWCNT samples), the presence of MWCNTs seems to play a key role in crushing the powder particles. Accordingly, while it seems that at the lower milling rates the powder crushing phenomenon has slowly progressed, higher milling rate and time have led to intensified crushing and plastic deformation of the $\mathrm{Al}$ and $\mathrm{Mg}$ particles. Hence, the semi-spheroidal morphology of the mentioned particles has been replaced by the flake-type morphology, which confirms the extensive progression of the plastic deformation.

The 2-step milling approach which is used for ball-milling of the double milled samples has led to finer particles of the final composite in AI-Mg-MWCNT samples compared to other sample groups, according 
to Fig. 4. Also in the last series, increasing the milling rate and time seem to have stronger effects on the reducing particle size of the samples, compared to other sample groups. Hence, as can be comparatively seen in Fig. 4, the finest composite powders have been obtained through the 2-step milling process.

(a)
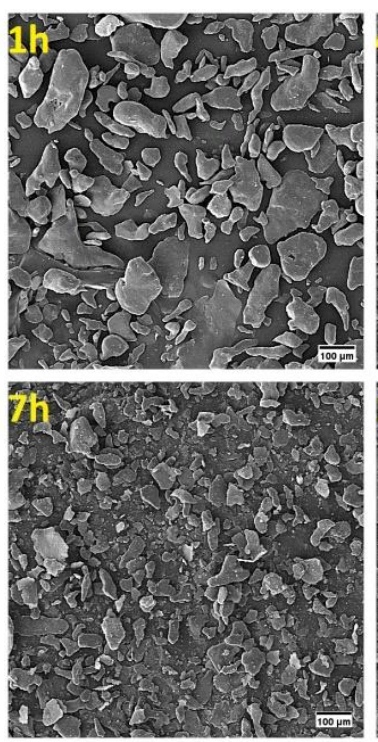
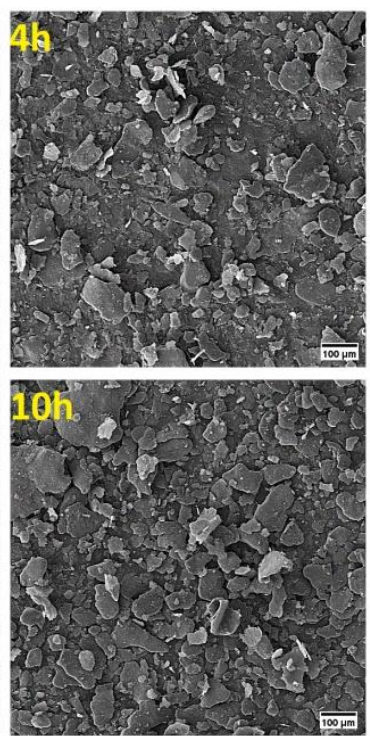

(b)
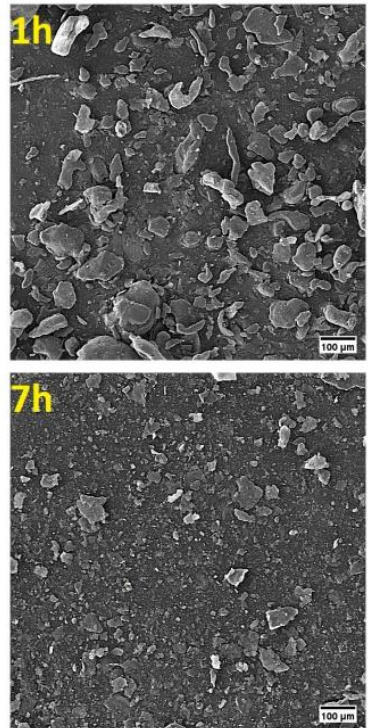
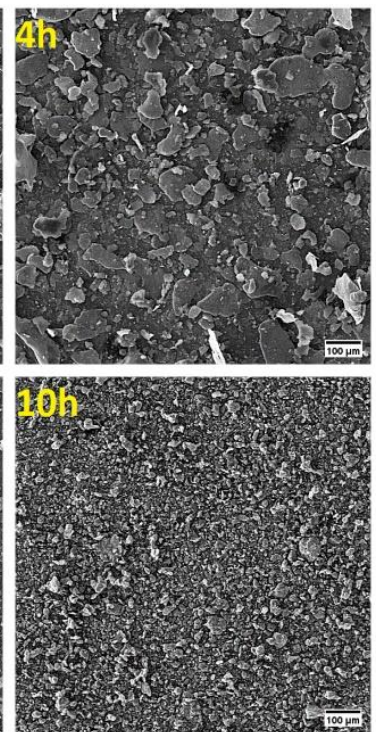

Fig. 2. SEM micrographs of the Al-Mg powder mixtures ball-milled at (a) $300 \mathrm{rpm}$ and (b) $400 \mathrm{rpm}$.

(a)
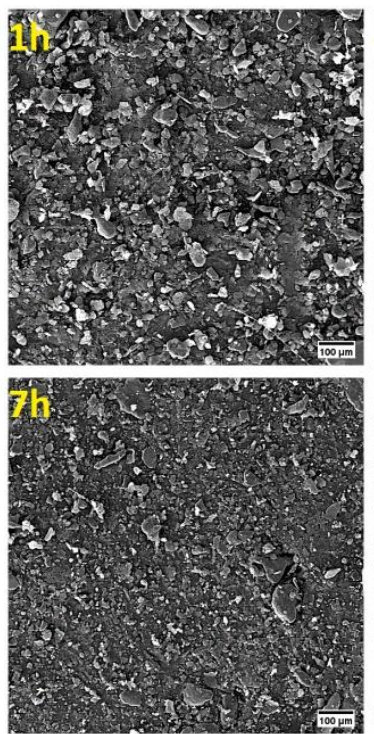
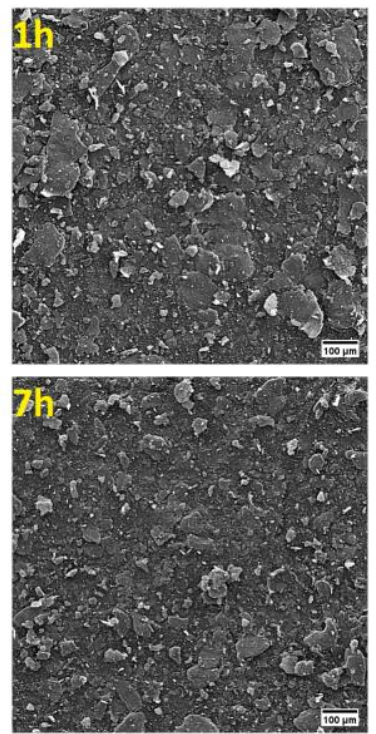

(b)
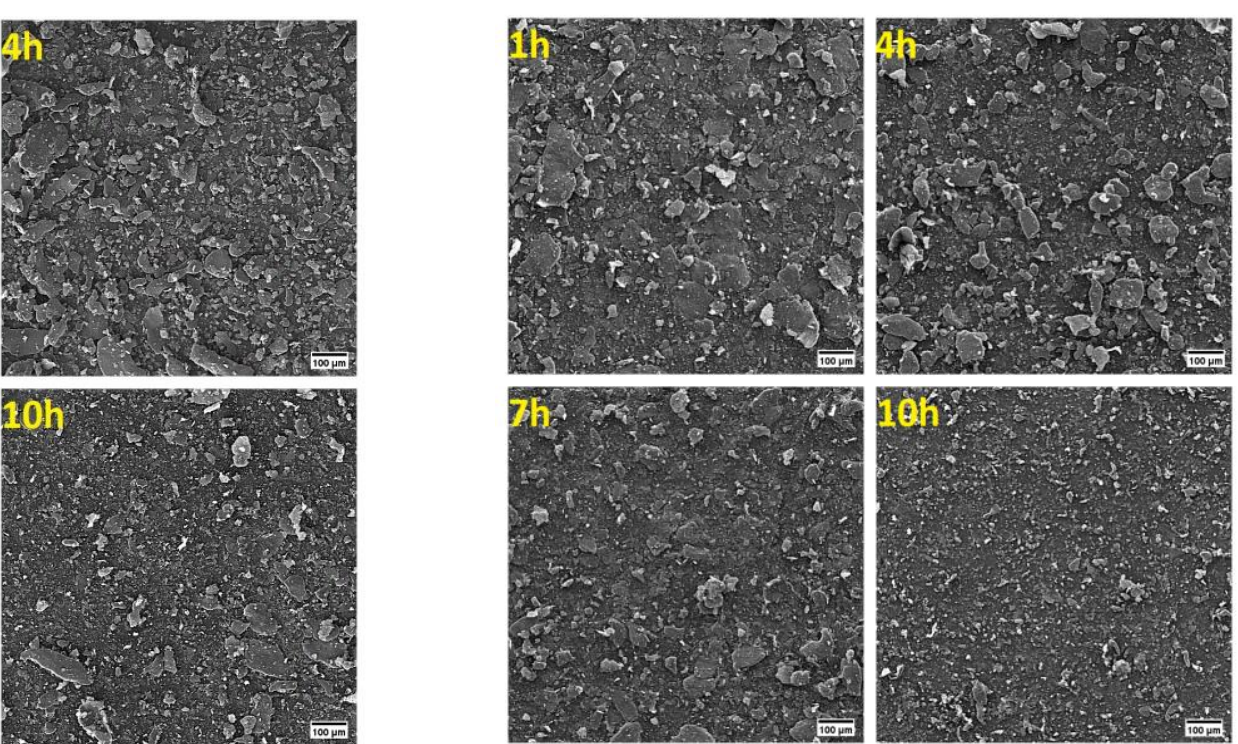

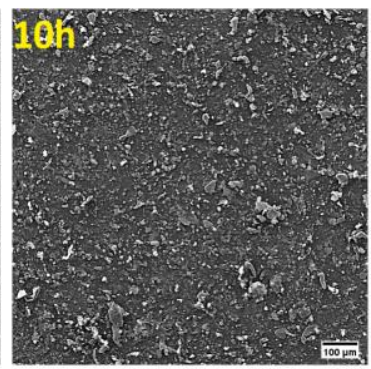

Fig. 3. SEM micrographs of the MM Al-Mg-MWCNT powder mixtures ball-milled at (a) $300 \mathrm{rpm}$ and (b) $400 \mathrm{rpm}$. 
(a)
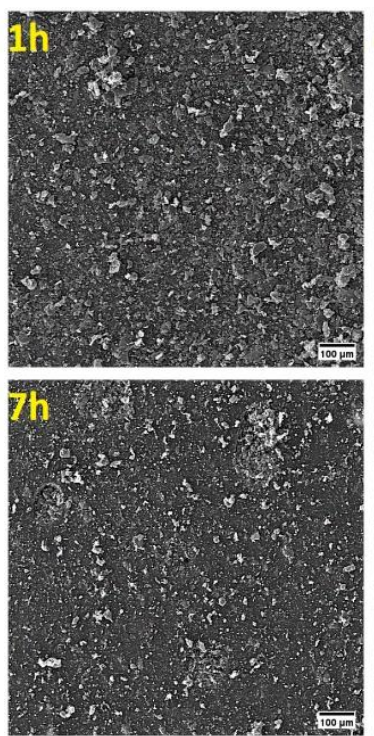
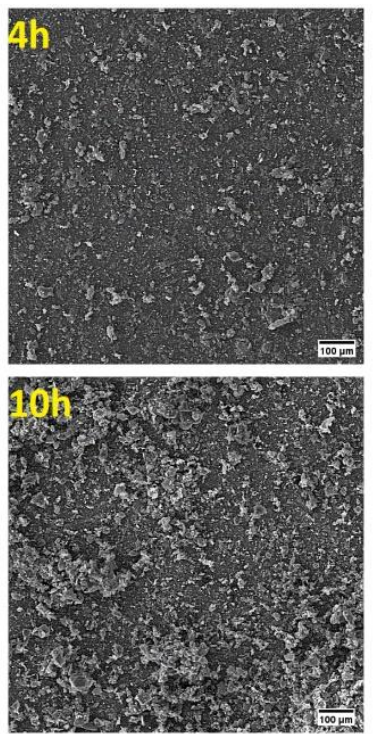

(b)
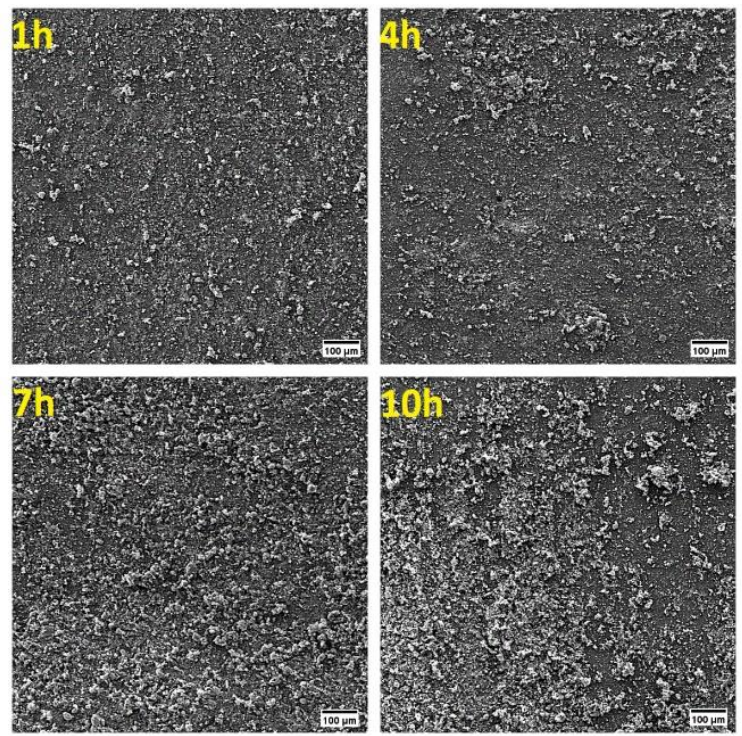

Fig. 4. SEM micrographs of the double milled Al-Mg-MWCNT powder mixtures ball milled at (a) $300 \mathrm{rpm}$ and (b) $400 \mathrm{rpm}$.

Fig. 5 shows the FESEM micrographs and related EDS elemental maps of the milled Al-Mg mixtures for 10 $\mathrm{h}$ in different milling rates. According to Fig. $5 \mathrm{a}$, it can be found that a homogenous distribution of the particles has been achieved. While the particle size of the mixture still seems to be large, no signs of particles' cold-welding and agglomeration are also observed in the mixture milled at $300 \mathrm{rpm}$. However, the particles' distribution and crushing seems to be improved in sample milled at $400 \mathrm{rpm}$, which can be attributed to higher milling time (Fig. 5b).

The FESEM micrographs on MM Al-Mg-MWCNT powder mixture in different magnifications are presented in Figs. 6 and 7. While the MMCNTs have agglomerated on the surface of the Al and Mg particles in sample milled for $1 \mathrm{~h}$ (Fig. 6a), increasing the milling time to $10 \mathrm{~h}$ seems to promote the MWCNT entrapment in the structure of the composite powders and decreases the MWCNTs. Fig. 6b confirms the decreased agglomeration of MWCNTs at the milling rate of $400 \mathrm{rpm}$ and relatively more homogenous distribution of MWCNT clusters. Higher magnification of the mentioned figure which is provided in Fig $7 \mathrm{~b}$ also addresses the shortening of the milled MWCNTs compared to their initial length as well as their length in sample milled at $300 \mathrm{rpm}$ (Fig. 7a). According to Fig. 7b, it is also worth to note that the entrapment of MWCNTs in the milled composite powders has been intensified, as MWCNTs cannot be well-distinguished at the sample milled at $400 \mathrm{rpm}$ for 10 hours.

According to Fig. 8, homogenous particle distributions without any meaningful difference can be observed in both of the samples milled for 10 hours, which addresses the minimum effect of milling rate on the particle distribution in 10 hours-milled samples. The FESEM nanograph of the Al-Mg-MWCNT powder mixture milled for 10 hours at $400 \mathrm{rpm}$, confirms the intensified crushing of the Al-Mg particles, shortened MWCNTs, and favorable distribution of the MWCNTs in the Al-Mg composite powders (Fig. 9b). 
(a)
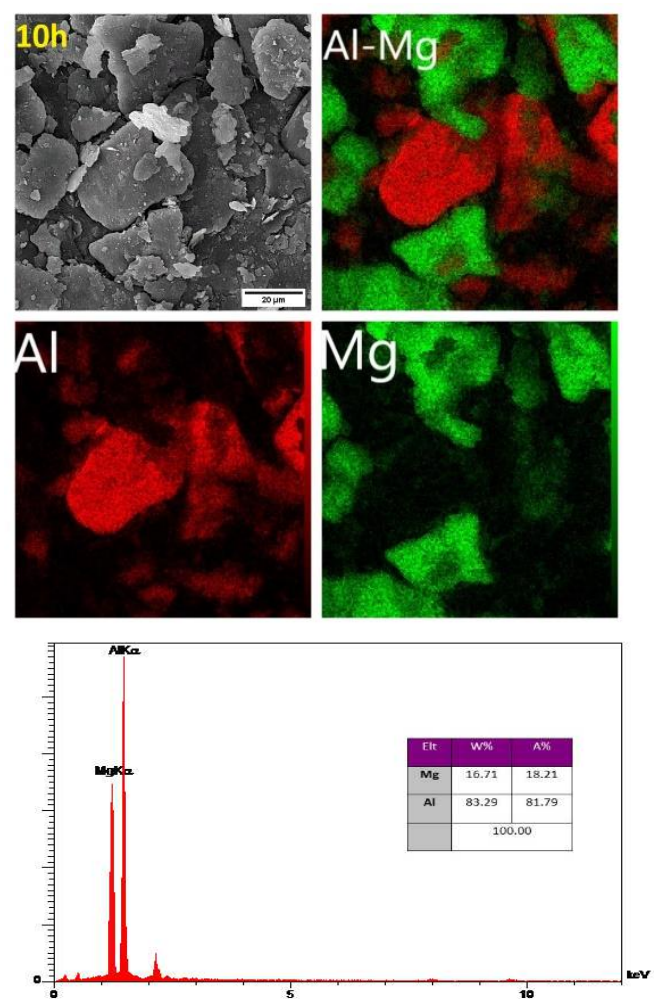

(b
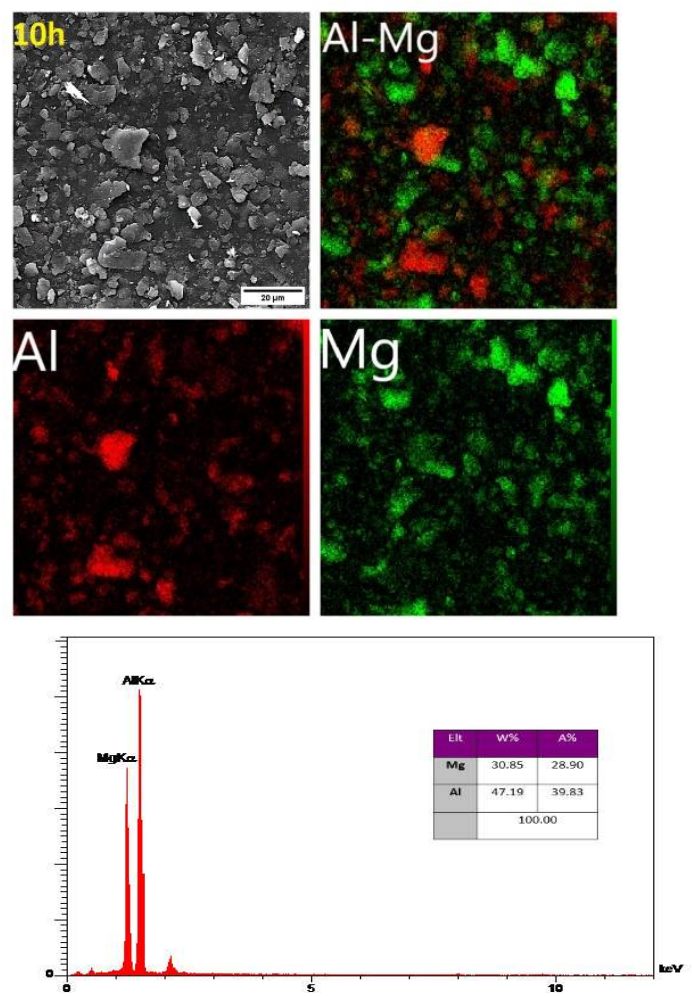

Fig. 5. FESEM micrographs and related EDS elemental maps of the milled Al-Mg powder mixtures in 10 hours at (a) $300 \mathrm{rpm}$ and (b) $400 \mathrm{rpm}$.

(a)
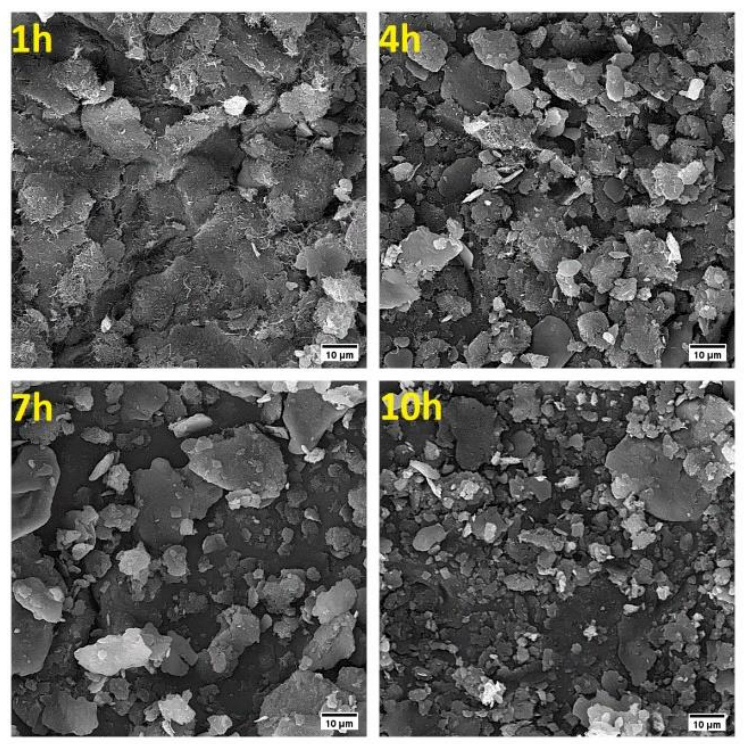

(b)
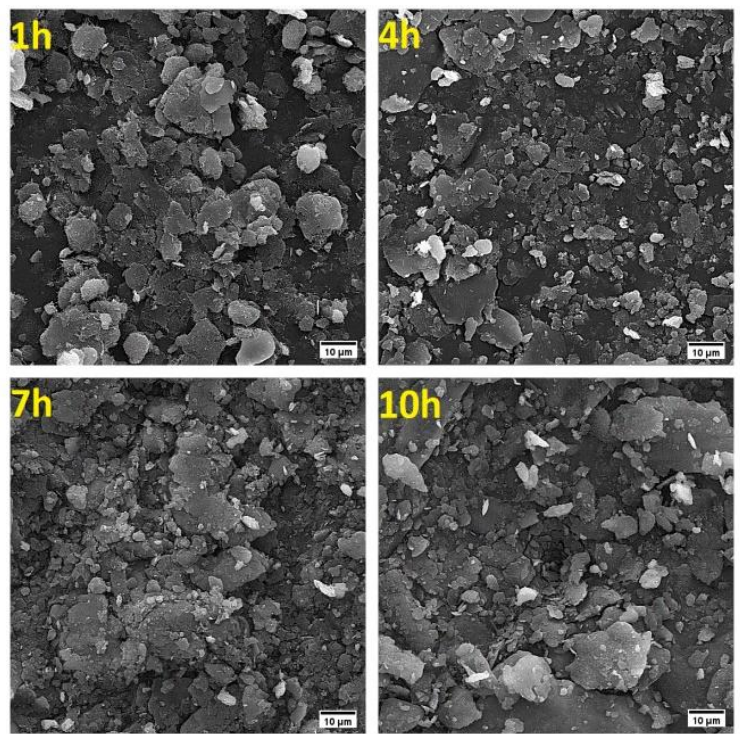

Fig. 6. FESEM micrographs of MM Al-Mg-MWCNT composite powders milled at (a) $300 \mathrm{rpm}$ and (b) 400 rpm. 
(a)
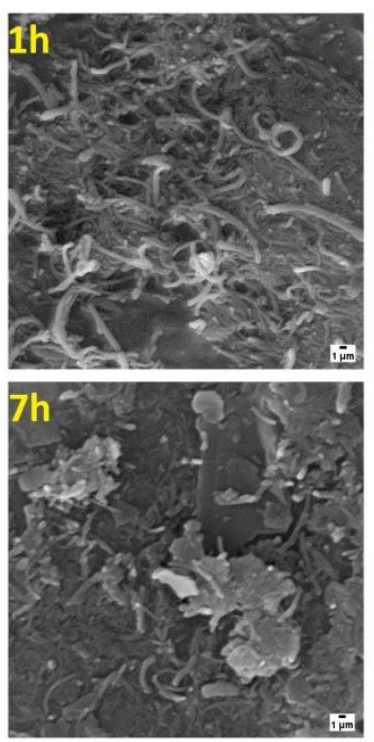

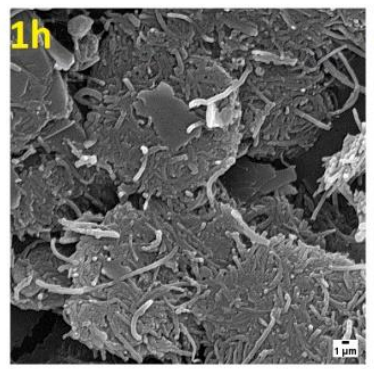

(b)
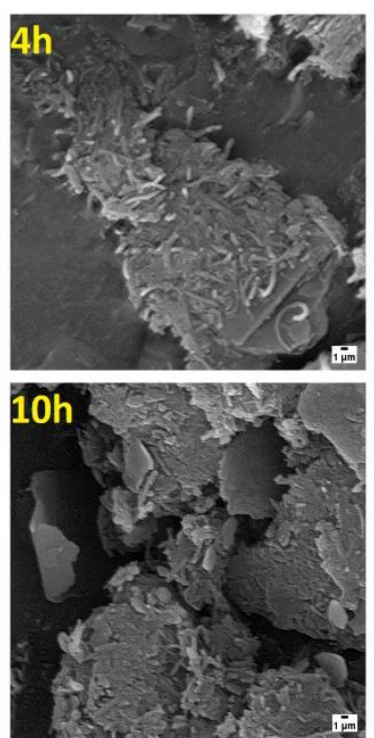
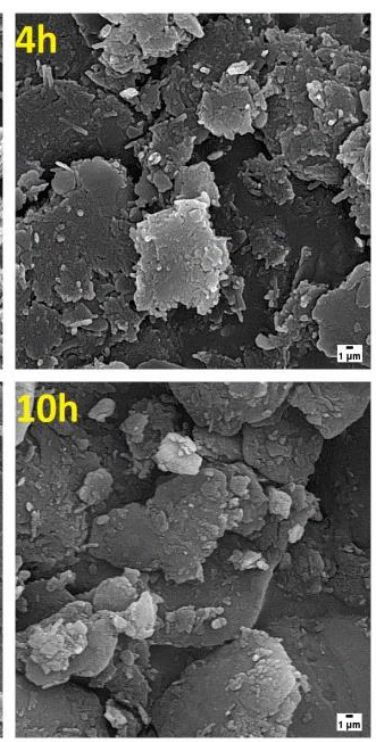

Fig. 7. FESEM micrographs of MM Al-Mg-MWCNT composite powders milled at (a) $300 \mathrm{rpm}$ and (b) 400 rpm in higher magnification than Fig. 6.

(a)
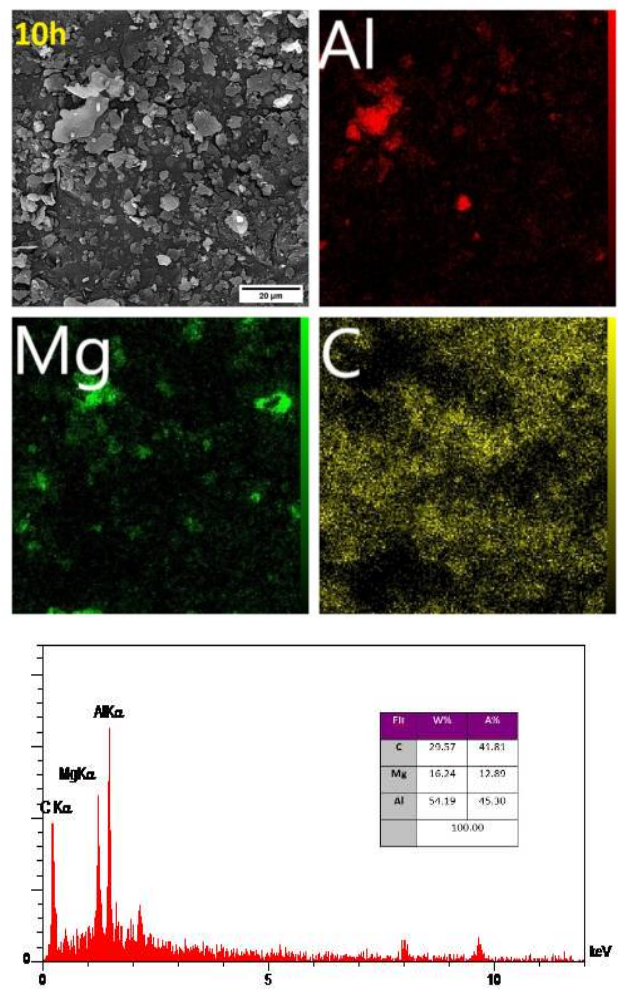

(b)
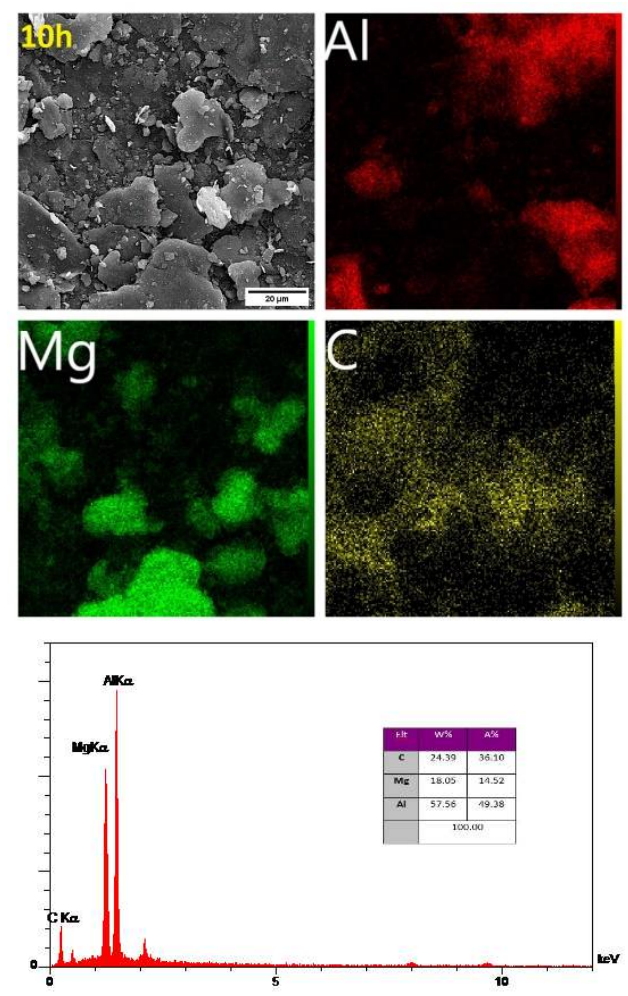

Fig. 8. FESEM micrographs and related EDS elemental maps of the MM Al-Mg-MWCNT powder mixtures milled for 10 hours at (a) $300 \mathrm{rpm}$ and (b) $400 \mathrm{rpm}$. 
(a)

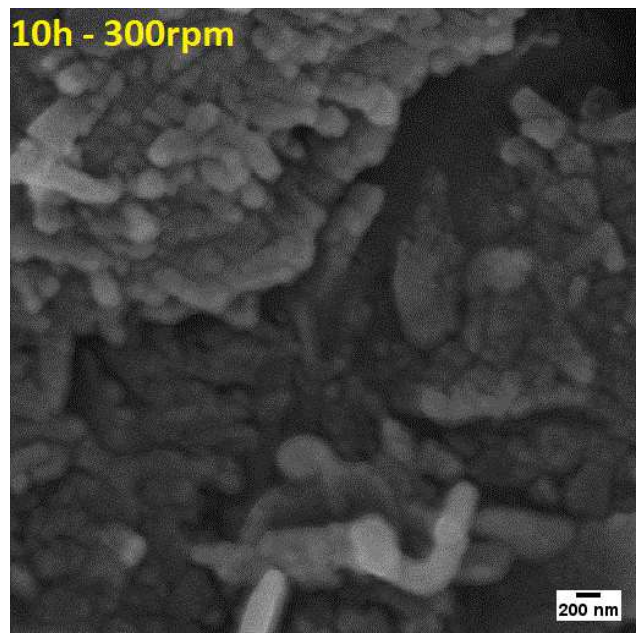

(b)

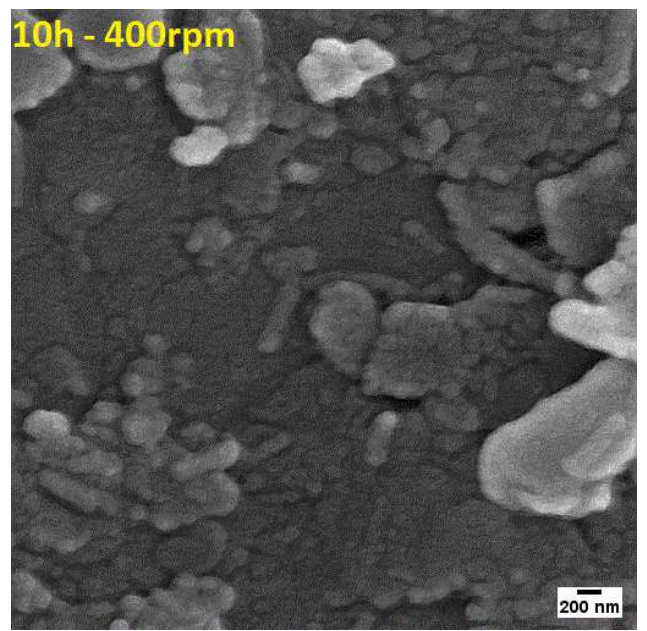

Fig. 9. FESEM nanographs of the MM Al-Mg-MWCNT powder mixtures milled for 10 hours at (a) $300 \mathrm{rpm}$ and (b) $400 \mathrm{rpm}$.

The FESEM micrographs of double milled composite powders are presented in Fig. 10. According to Fig. $10 \mathrm{a}$ it can be paraphrased that increasing the milling time not only has resulted in decreased particle of Al and Mg powders, but also promoted the de-agglomeration and homogenized the distribution of the MWCNTs in the matrix. Enhancing the milling rate to $400 \mathrm{rpm}$, has also resulted in further decrease of the particles' size as well as the intensified de-agglomeration of MWCNTs, based on Fig. 10b. the EDS elemental maps of the double milled samples which are presented in Fig. 11, show better particle distribution in sample milled for $10 \mathrm{~h}$ at $400 \mathrm{rpm}$ (Fig. 11b) compared to other samples (Fig. 11a). The shortening of the MWCNTs is also indicated based on the elemental maps presented in Fig. 11. Higher magnification FESEM micrographs presented in Fig. 12 confirm the improved de-agglomeration of the MWCNTs and intensified entrapment of the MWCNTs in the composite powder particles, due to the increased milling time and rate. The FESEM nanographs of Fig. 13 also indicate that no MWCNT has remained on the surface of the composite powders (MWCNTs have fully entrapped in the matrix) in samples milled at $400 \mathrm{rpm}$ for $10 \mathrm{~h}$. the stabilized state of the cold-welding and crushing of the powders and the occurrence of plastic deformation in the powder particles have also resulted in better distribution and entrapment of the MWCNTs [17,25], based on Fig. 13. 
(a)
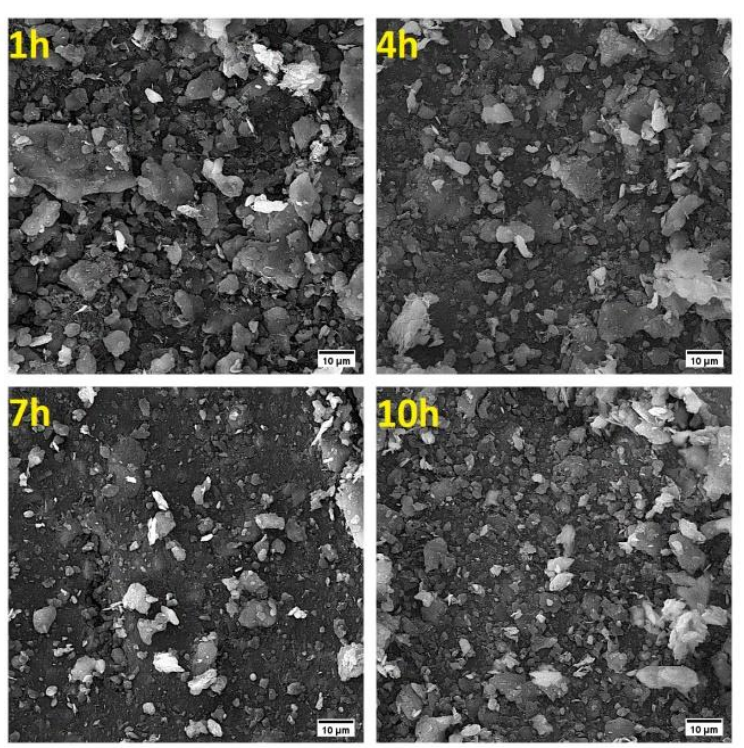

(b)
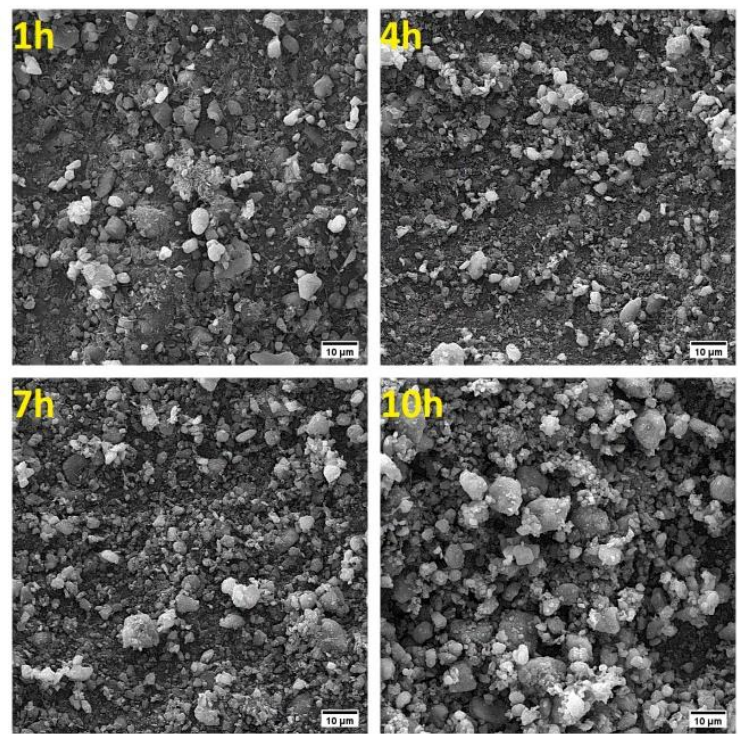

Fig. 10. FESEM micrographs of the double milled composite powders milled at (a) $300 \mathrm{rpm}$ and (b) 400 rpm.

(a)
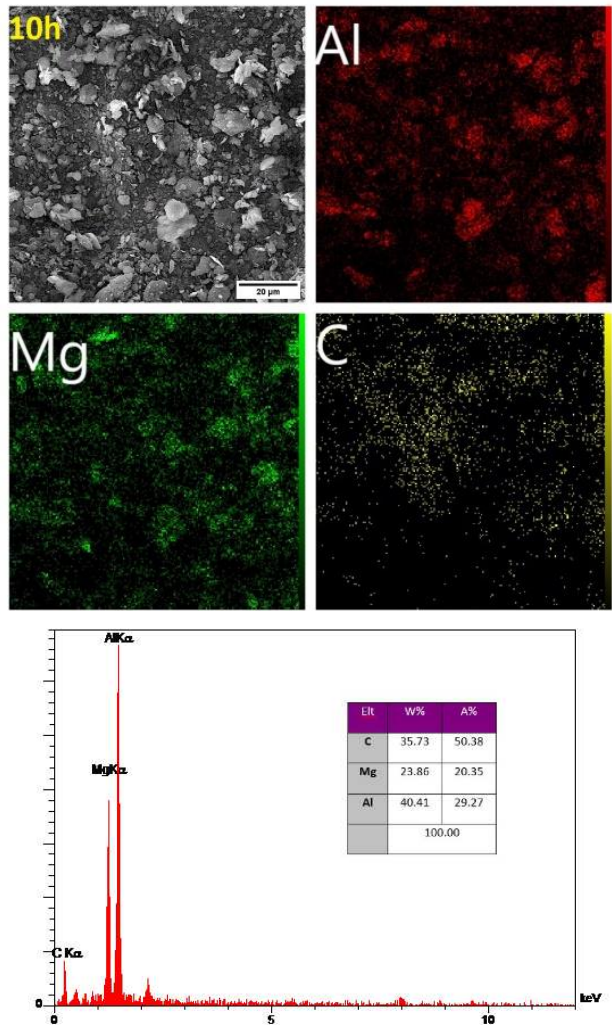

(b)
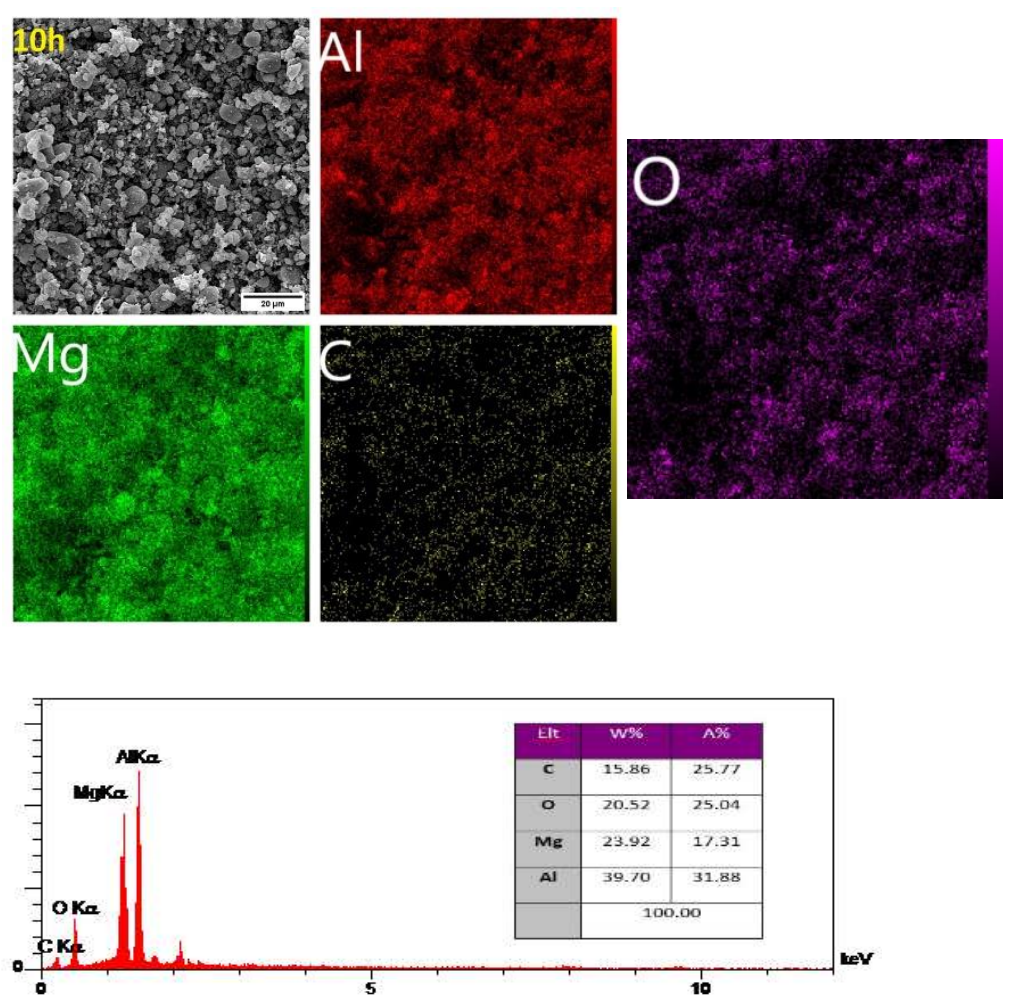

Fig. 11. FESEM micrographs and related EDS elemental maps of the double milled composite powders, processed for $10 \mathrm{~h}$, at (a) $300 \mathrm{rpm}$ and (b) $400 \mathrm{rpm}$. 
(a)
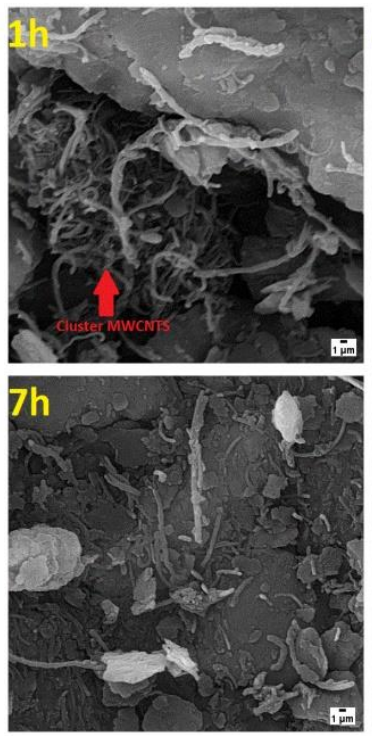
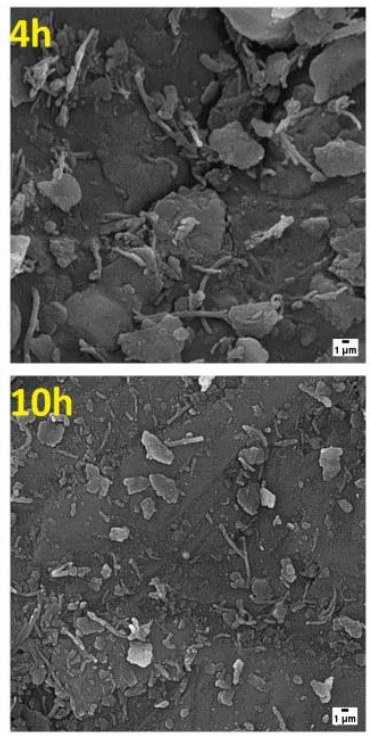

(b)
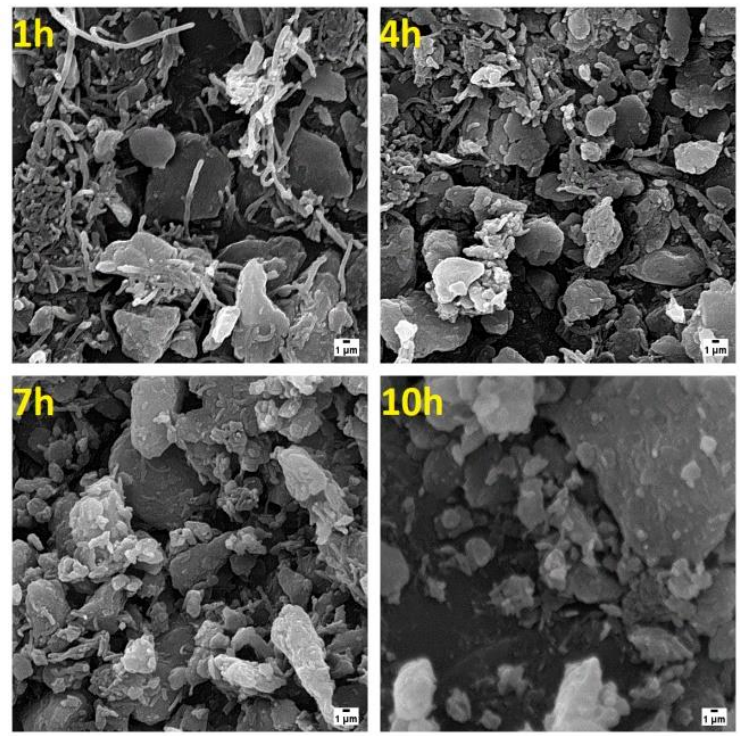

Fig. 12. FSEM micrographs at higher magnification of the double milled composite powders processed at (a) $300 \mathrm{rpm}$ and (b) $400 \mathrm{rpm}$.

(a)

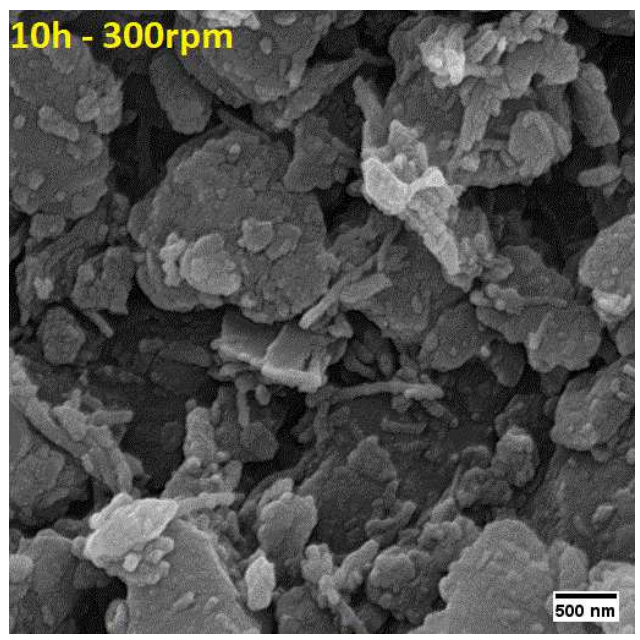

(b)

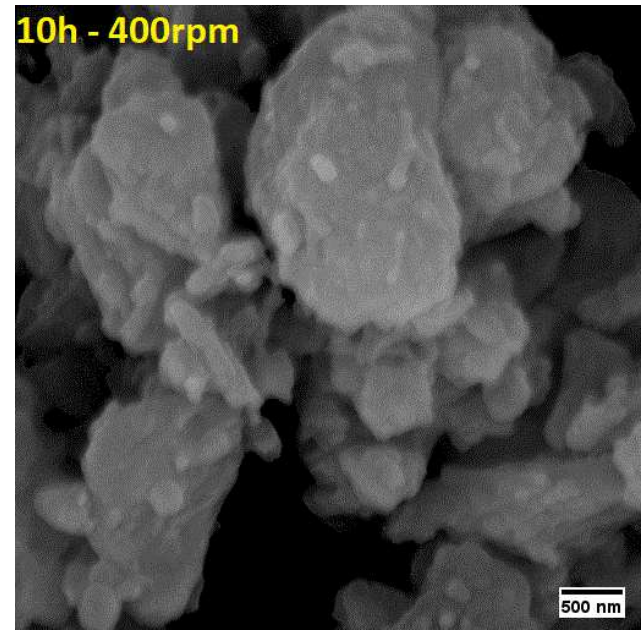

Fig. 13. FESEM nanographs of the double milled composite powders processed for $10 \mathrm{~h}$, at (a) $300 \mathrm{rpm}$ and (b) $400 \mathrm{rpm}$.

\subsection{Structural analysis}

The phase analysis of the Al-Mg and Al-Mg-MWCNT composite powders were carried out based on the XRD patterns of the samples. Fig. 14 shows the XRD patterns of the milled Al-Mg composite powders. As can be seen, while the only detected peaks belong to Al and $\mathrm{Mg}$ phases and the peak intensities are decreased at the higher milling rate, no other peaks are detected, which addresses the occurrence of no 
chemical reaction between $\mathrm{Al}$ and $\mathrm{Mg}$. Kwangjae Park et. al have shown that the ball-milling of Al-Mg powder mixtures for $12 \mathrm{~h}$ at $200 \mathrm{rpm}$ would not result in any chemical reaction between two metals [10]. Similar outcome has also obtained in this study, even a higher milling rate up to $400 \mathrm{rpm}$.

(a)

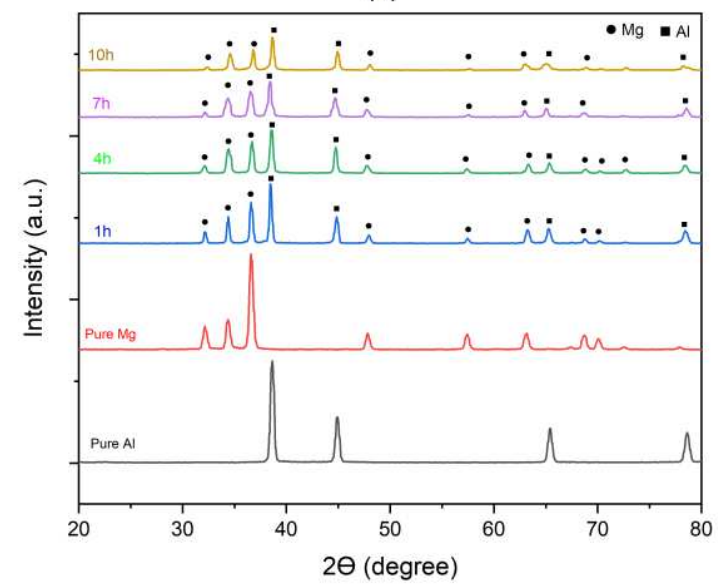

(b)

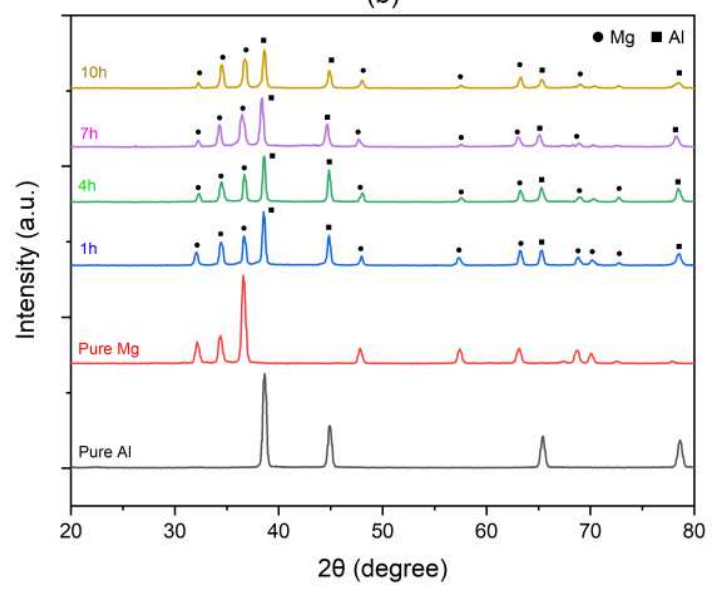

Fig. 14. XRD patterns of the milled Al-Mg composite powders at (a) $300 \mathrm{rpm}$ and (b) $400 \mathrm{rpm}$.

The XRD patterns of the MM Al-Mg-MWCNT composite powders are presented in Fig. 15. As can be seen, the only difference between the XRD patterns of this group with those of milled Al-Mg samples is the appearance of MWCNTs peaks. Hence, it can be paraphrased that the presence on MWCNTs has not resulted in any reactions between $\mathrm{Al}, \mathrm{Mg}$, and carbon (MWCNTs), while the intensity of the peaks has decreased via increased milling time and rate. Comparing the XRD patterns of MM Al-Mg-MWCNT composite powders milled at $300 \mathrm{rpms}$ and $400 \mathrm{rpm}$, the peaks of MWCNTs seem to be disappeared in higher milling rate. Such a result has been previously reported by A. D. Rud et. al for similar powders milled for $3 \mathrm{~h}$ at $400 \mathrm{rpm}[26]$.

The XRD patterns of the double milled group are presented in Fig. 16. As can be seen in Fig. 16a, the phase arrangement of double milled samples resembles that of MM Al-Mg-MWCNT group. The only difference is the lower intensity of peaks in double milled samples, which can be attributed to the 2-step milling process. Decreased peak intensity is also the only significant impact of the milling time on the phase arrangement of the double milled samples. However, the arrangement of the peaks in the XRD pattern presented in Fig. 16b shows obvious differences with the other samples of the double milled group, and confirms the formation of intermetallic phases in the sample milled at $400 \mathrm{rpm}$. In other words, the higher milling rate in this sample has promoted the reaction between $\mathrm{Al}$ and $\mathrm{Mg}$, and resulted in the formation of intermetallic phases such as $\mathrm{Al}_{0.56} \mathrm{Mg}_{0.44}, \mathrm{Al}_{12} \mathrm{Mg}_{17}, \mathrm{Al}_{2.4} \mathrm{Mg}_{0.4} \mathrm{O}_{4}, \mathrm{AlMg}$ and $\mathrm{Al}_{2} \mathrm{O}_{3}$. 
(a)

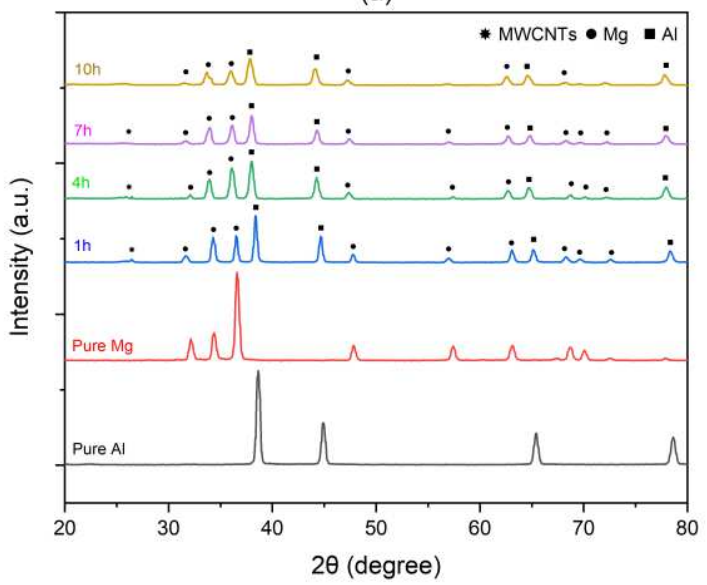

(b)

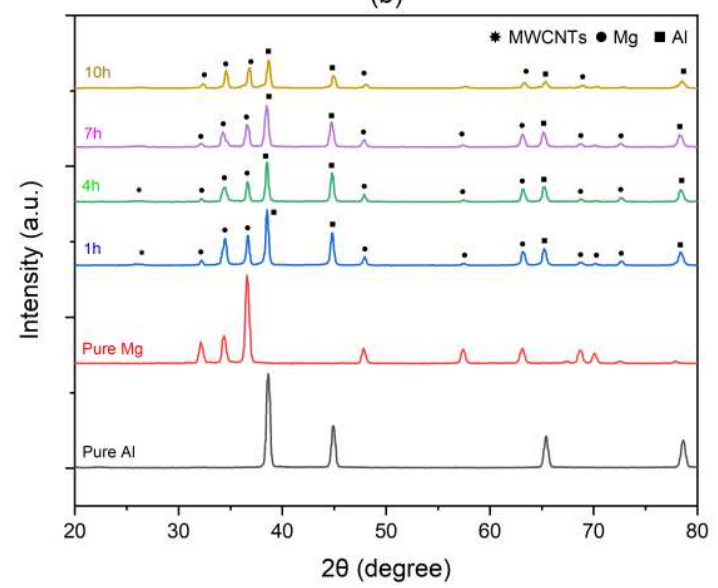

Fig. 15. XRD patterns of the MM Al-Mg-MWCNT composite powders at (a) $300 \mathrm{rpm}$ and (b) $400 \mathrm{rpm}$.

(a)

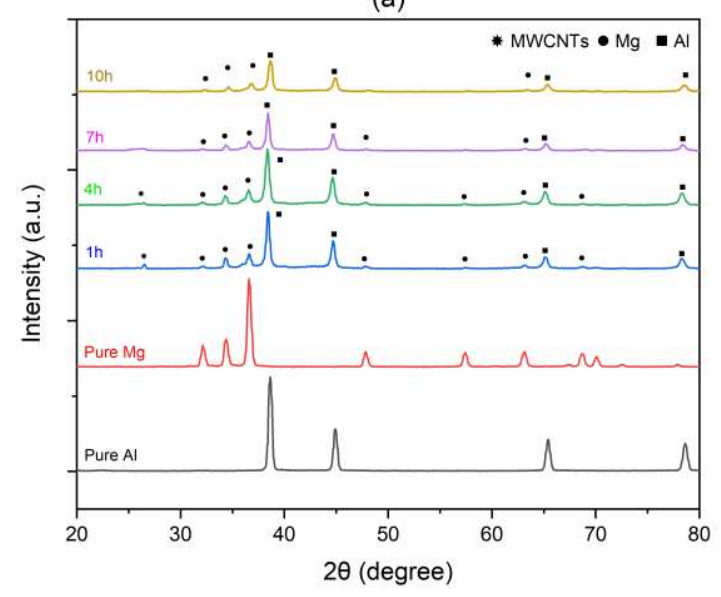

(b)

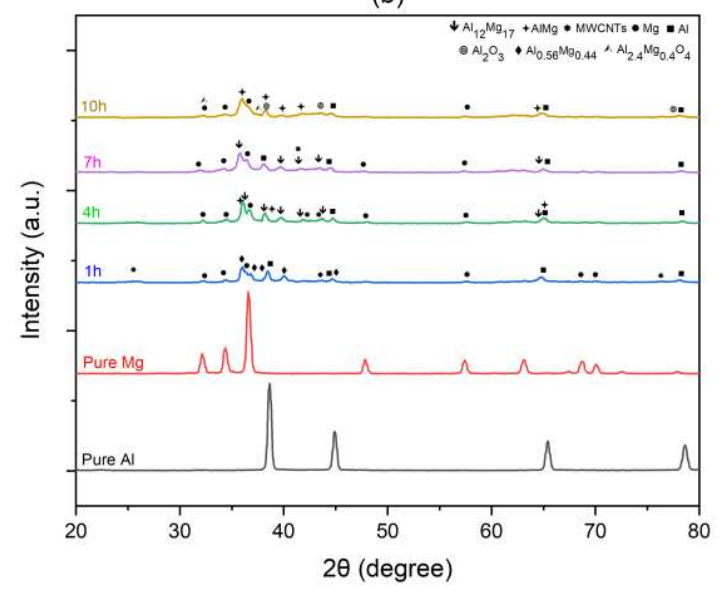

Fig. 16. XRD patterns of the double milled Al-Mg-MWCNT composite powders at (a) $300 \mathrm{rpm}$ and (b) 400 rpm.

The variations of crystallite size and lattice parameters of the milled composite powders at two different milling rates and four different milling times are depicted in Fig. 17. According to Fig. 17a, it can be seen that in the milled Al-Mg composite powders milled at $300 \mathrm{rpm}$, increasing the milling time can reduce the Al crystallite size from $34.69 \mathrm{~nm}$ in pure aluminum powder to $26.27 \mathrm{~nm}$ in the sample milled for 10 hours. Similarly, in the samples milled at $400 \mathrm{rpm}$, the Al crystallite size has reduced to $23.03 \mathrm{~nm}$ after 10 hours of milling process. in the other words, at a constant milling time, increased milling rate has resulted in about $12 \%$ reduction in the crystallite size of aluminum. The addition of MWCNTs has resulted in dramatically decrease in the crystallite size of aluminum, from 34.69 to 25.52 and $24.73 \mathrm{~nm}$ in samples milled for only 1 hour at 300 and $400 \mathrm{rpm}$, respectively. Increasing the milling time to $10 \mathrm{~h}$ has resulted in 
$40 \%$ and $42 \%$ decrease in the crystallite size of aluminum in MM Al-Mg-MWCNT samples milled at 300 rpm and 400 rpm, respectively.

Further decrease in the Al crystallite size has been achieved in double milled samples, based on Fig. 17a. For example, the Al crystallite sizes of $22.50 \mathrm{~nm}$ and $19.82 \mathrm{~nm}$ have been achieved in samples milled for only 1 hour at $300 \mathrm{rpm}$ and $400 \mathrm{rpm}$, respectively. While in the sample milled for 10 hours at $300 \mathrm{rpm}$ the Al crystallite size has reduced to $10.05 \mathrm{~nm}$, increasing the milling rate to $400 \mathrm{rpm}$ has resulted in Al crystallite size of about $5.86 \mathrm{~nm}$. Such outcomes can be attributed to the two-step milling time in which, higher energy is applied on the powder particles and not only intensifies the crushing of the powders, but also promotes the crystalline defects such as spot defects and dislocations [27].

According to Fig. 17b, decreasing the Al crystallite size has resulted in increased lattice parameters of all the samples. While the increased lattice parameter has slowly occurred in samples of milled Al-Mg and MM Al-Mg-MWCNT groups, a sharp slope is seen in the lattice parameter diagram of double milled samples. Such observations may also address the formation of intermetallic phases and crystalline defects during the milling process.

(a)

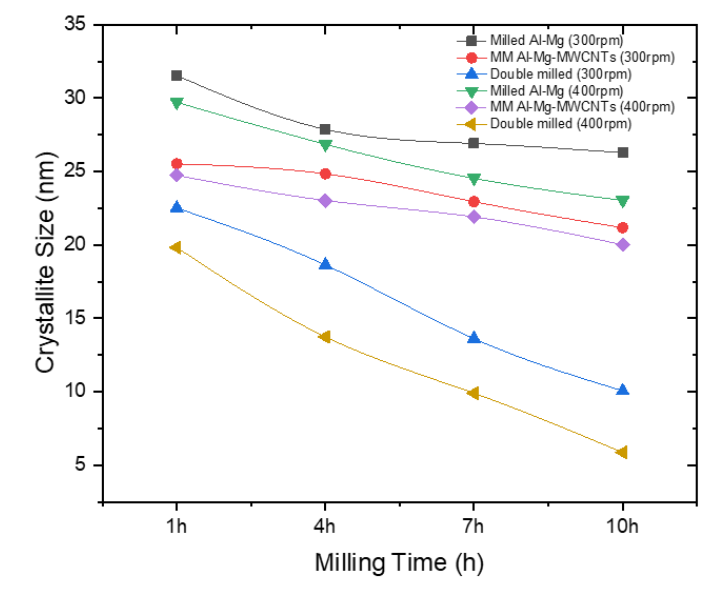

(b)

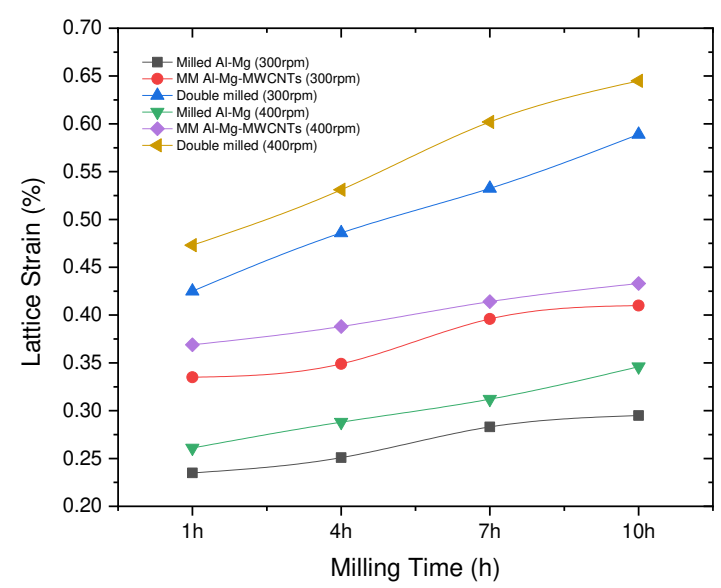

Fig. 17. (a) crystallite size and (b) lattice parameter of all the three groups of the milled composite powders.

\section{Conclusions}

The effects of milling parameters on the physical and microstructural characteristics of the milled Al-Mg composites powders reinforced with MWCNTs were investigated. Three different composite powder groups including milled Al-Mg (no MWCNTs added), MM Al-Mg-MWCNT, and double milled Al-MgMWCNT samples were prepared. The outcomes of this study can be concluded as follows:

1. In the MWCNT-free samples it was observed that at the milling rate of $300 \mathrm{rpm}$, increasing the milling time would result in decreased particle size. However, milling for 10 hours has found to cause increased 
particle size, which was attributed to the cold-welding of the particles in this sample. Increasing the milling time and rate is found to intensify the particle crushing and improve the distribution of the particles. Microstructural investigations of the milled Al-Mg samples also indicated that no intermetallic phases were formed, while the Al crystallite size was decreased from 34.69 to 26.27 and $23.03 \mathrm{~nm}$ for samples milled at $300 \mathrm{rpm}$ and $400 \mathrm{rpm}$, respectively.

2. Morphological investigations of MM Al-Mg-MWCNT and double milled Al-Mg-MWCNT samples indicated that enhancing the milling time and rate would lead to decreased particle size in both samples. It can also de-agglomerate and promote MWCNTs to enter the matrix. Comparatively, improved outcomes were obtained in double milled Al-Mg-MWCNT samples. The formation of $\mathrm{Al}_{0.56} \mathrm{Mg}_{0.44}, \mathrm{Al}_{12} \mathrm{Mg}_{17}$, $\mathrm{Al}_{2.4} \mathrm{Mg}_{0.4} \mathrm{O}_{4}$, $\mathrm{AlMg}$ and $\mathrm{Al}_{2} \mathrm{O}_{3}$ phases was also validated in double milled Al-Mg-MWCNT samples milled at $400 \mathrm{rpm}$.

3. Analyzing the XRD patterns of the samples indicated that the Al crystallite size is continuously decreased due to the intensifying plastic deformation of the particles, and finally dropped to $5.86 \mathrm{~nm}$ in double milled Al-Mg-MWCNT sample milled for 10 hours at $400 \mathrm{rpm}$ (about $83 \%$ decrease). 


\section{References}

[1] S.R. Bakshi, D. Lahiri, A. Agarwal, Carbon nanotube reinforced metal matrix composites, Int. Mater. Rev. 55 (2010) 41-64.

[2] Farhad Ostovan, Khamirul Amin Matori, Effects of CNTs content and milling time on mechanical behavior of MWCNT-reinforced aluminum nanocomposites, Materials Chemistry and Physics (2015) 1-7.

[3] Heekyu Choi, Lin Wang, Preparation by mechanical alloying of Al powders with single-, double-, and multi-walled carbon nanotubes for carbon/metal nanocomposites, Composites Science and Technology 74 (2013) 91-98.

[4] A. Esawi, K. Morsi, Dispersion of carbon nanotubes (CNTs) in aluminum powder, Composites: Part A 38 (2007) 646-650.

[5] J.D. Kim, J.H. Kim, X.H. Zhang, et al., Control of mechanical properties according to content ratio of copper coated carbon nanotubes in aluminum composites, J. Chem. Chem. Eng. 6 (2012) 455-461.

[6] X. Cheng, J.S. Kim, C.W. Park, Multiwall carbon nanotube/copper porous coating for heat transfer application, Surf. Eng. 31 (2015) 723-732.

[7] K. Chu,W. Qingying, J. Chengchang, et al., Fabrication and effective thermal conductivity of multiwalled carbon nanotubes reinforced Cu matrix composites for heat sink applications, Compos. Sci. Technol. 70 (2010) 298-304.

[8] Akshay Kumar, M.K. Banerjee, Development of a novel MWCNT reinforced iron matrix nanocomposite through powder metallurgy route, Powder Technology 331 (2018) 41-51.

[9] Xiang Zhang, Naiqin Zhao, The superior mechanical and physical properties of nanocarbon reinforced bulk composites achieved by architecture design - A review, Progress in Materials Science 113 (2020) 100672.

[10] Kwangjae Park, Jehong Park, Effect of intermetallic compound on the Al-Mg composite materials fabricated by mechanical ball milling and spark plasma sintering, Journal of Alloys and Compounds 739 (2018) $311 \mathrm{e} 318$.

[11] Kiahosseini, S.R., Ahmadian, H. Effect of residual structural strain caused by the addition of Co3O4 nanoparticles on the structural, hardness and magnetic properties of an $\mathrm{Al} / \mathrm{Co3O} 4$ nanocomposite produced by powder metallurgy. Int J Miner Metall Mater 27, 384-390 (2020).

[12] Katsuyoshi Kondoh, Hiroyuki Fukuda, Microstructural and mechanical behavior of multi-walled carbon nanotubes reinforced Al-Mg-Si alloy composites in aging treatment, CARBON 72 (2014) 15-21.

[13] Rub Nawaz Shahid, Sergio Scudino, Microstructure and Mechanical Behavior of Al-Mg Composites Synthesized by Reactive Sintering, Metals 2018, 8(10), 762.

[14] Gul Tosun, Mehmet Kurt, The porosity, microstructure, and hardness of Al-Mg composites reinforced with micro particle SiC/Al2O3 produced using powder metallurgy, Composites Part B 174 (2019) 106965.

[15] Ahmadian, H., SallakhNiknezhad, R. The Effect of Shot Peening Duration on Corrosion Properties of Magnesium Alloy AZ91 in 3.5\% NaCl Solution. J. Inst. Eng. India Ser. D 102, 195-202 (2021). 
[16] M. H. Zayan, O. M. Jamjoom, High-Temperature Oxidation of Al-Mg Alloys, Oxidation of Metals, VoL 34, Nos. 3/4, 1990.

[17] Wu G, Dash K, Galano ML, O’Reilly KAQ, Oxidation studies of Al alloys: Part II AI-Mg alloy, Corrosion Science (2019).

[18] M.A. Eltaher, A.Wagih, A. Melaibari, A. Fathy, G. Lubineau, Effect of Al2O3 particles on mechanical and tribological properties of Al-Mg dual-matrix nanocomposites, Ceramics International (2019).

[19] Íris Carneiro, Sónia Simões, Effect of Morphology and Structure of MWCNTs on Metal Matrix Nanocomposites, Materials 2020, 13(23), 5557.

[20] Lavish K. Singh, Alok Bhadauria, Spark plasma sintered Al-0.5 wt\% MWCNT nanocomposite: Effect of sintering pressure on the densification behavior and multi-scale mechanical properties, Diamond \& Related Materials 91 (2019) 144-155.

[21] M.R. Akbarpour, S. Alipour, M. Najafi , Tribological characteristics of self-lubricating nanostructured aluminum reinforced with multi-wall CNTs processed by flake powder metallurgy and hot pressing method. Diamat (2018).

[22] F. Rikhtegar, S.G. Shabestari, Microstructural evaluation and mechanical properties of Al-CNT nanocomposites produced by different processing methods, Journal of Alloys and Compounds Volume 723, 5 November 2017, Pages 633-641.

[23] M.R. Akbarpour, A. Pouresmaeil , The influence of CNTs on the microstructure and strength of Al-CNT composites produced by flake powder metallurgy and hot pressing method. Diamat (2018).

[24] C. Suryanarayana, M. Grant Norton, X-Ray Diffraction - A Practical Approach, Plenum Press, New York, 1998.

[25] Behnam Nazerian Khozani, Aliasghar Abuchenari, Effects of $\mathrm{Mg}$ and MgO Nanoparticles on Microstructural and Mechanical Properties of Aluminum Matrix Composite Prepared via Mechanical Alloying, Journal of Composites and Compounds 3 (2021) 91- 98.

[26] Rud, A.D., Kirian, I.M., Lakhnik, A.M. et al. Synthesis of the metastable Al3Mg phase in Mg Al-C system by mechanical alloying. Appl Nanosci (2021).

[27] C. Suryanarayana, Mechanical alloying and milling, Progress in materials science 46(1-2) (2001) 1-184. 